\title{
Interdisciplinaridade e a orientação do educador
}

\author{
Regina Helena Lima Caldana*
}

\section{RESUMO}

Este trabalho tem por objetivo analisar e discutir como vem se processando a resposta dos profissionais (especialemente dos psicólogos) a uma procura de orientação para a educação da criança. Para tanto recorre-se a uma abordagem interdisciplinar que permite, ao mesmo tempo, analisar: a) as dificuldades e problemas experienciados pelos adultos no papel de socializadores; b) os diferentes tipos de orientação "técnicas e científicas" a eles fornecidas; c) as necessidades de apoio em outras áreas do saber, especialmente a história da criança, da educação e da família, para compreender o contexto e propor melhores estratégias de orientação aos educadores.

\section{INTRODUÇÃO}

O papel do educador comporta tarefas que se alteram segundo o momento e 0 contexto, tendo a conotação de serem sócio-histórico e culturalmente determinadas. E, imbricadas com a prática estão as teorias, cujo confronto permite estabelecer um contraponto que, ao sintetizar idéias e discutir valores, permite e facilita a própria transformação do agir dos educadores, estejam eles na escola ou na família.

Ao que possam pesar todas as dificuldades e talvez até por elas serem muitas, a atividade de educar tem sido vista como extremamente absorvente eque demanda, mais do que tempo e disponibilidade, uma atenção capaz de gerar a aprendizagem do agir mais adequado e produtivo. $\mathrm{E}$, colocado desta forma, torna-se necessário admitir que a ação dos educadores visa objetivos imediatos e mediatos, e que estes, mais até do que as práticas, são determinados por valores sócio-históricoe culturalmente estabelecidos.

Fecha-se o círculo e abre-se uma discussão, quando nada porque a tarefa dos educadores se mostra atualmente especialmente árdua pelas dúvidas e incertezas que a acompanham.

Tem sido comum admitir que essa situação vem de uma inversão radical de papéis: os socializadores teriam passado de tiranos a escravos, ocorrendo o inverso com as crianças; e, na raiz deste problema estaria a difusão maciça de informaçðes sobre

\footnotetext{
"Profa. do Depto. de Psicologia e Educação da Faculdade de Filosofia, Ciências e Letras de Ribeirão Preto-USP.
}

Paidéia, FFCLRP-USP, Rib. Preto, 7, Agosto/1994. 
educaçao infantil vinculadas à psicologia confundindo os pais e levando a uma postura excessivamente liberal, marcada ainda pela preocupação em não traumatizar, em não frustrar, cujo complemento é a culpa despertada por quaisquer atitudes que objetivem impor limites'

Não se pode negar certa validade a esta sequência de constatações. Da mesma forma não é possivel fugir a sérios questionamentos sobre a atuação dos profissionais da educação, inclusive os da área psi, com as orientaçðes que sem dúvida vêm fazendo parte do cotidiano da escola e da família.

A situação acima descrita precisa ser bem compreendida levando-se em conta o contexto em que ela se dá. Neste caso específico, muito tem contribuido uma reunião de conhecimentos históricos, sociológicos antropológicos e psicológicos que apontam para as dificuldades e vicissitudes do processo de modernização societária que se deu a partir dos anos 60 e 70 nos centros urbanos industrializados no Brasil (Romanelli, 1987). Algumas características desse processo ${ }^{2}$ merecem ser destacadas: em primeiro lugar, o constante confronto entre presente e passado, de tal forma que a busca do novo se dê em detrimento do antigo e que o passado e a memória deixem de ser elementos importantes na elaboração e ordenação das experiências vividas (Berman, 1987; Romanelli, op. cit.).

No caso da família mais especificamente, a sintonia com um ideário moderno ou com o tradicional pressupõe formas totalmente diversas de relacionamento e posicionamento entre seus membros. Se no modelo tradicional um conjunto de valores comuns ao grupo familiar deve prevalecer sobre todos os seus membros, que assim acatam papéis e regras externamente definidos, no ideário moderno prima a valorização da idiossincrasia, a inexistência (ou quase) de regras explícitas e externas, ficando a cargo de cada um decidir sua forma de agir de acordo com suas crenças particulares (Figueira, 1987).

Toda transição entre diferentes ordenamentos internos de valores e condutas é por si só desencadeadora de dúvidase, consequentemente de angústia. Mas na mudança do ideário tradicional para o moderno, essas duvidas e angústias ficam ampliadas pelas caracteristicas inerentes ao novo modelo adotado: as decisð̃es e posturas são colocadas na mão de cada educador; este deve fazer e refazer suas opçð̃es e condutas, porque nada vem pronto. Delineia-se assim um contexto, extremamente favorável à demanda do conhecimento psicológico; por ser afinado a um ideário moderno, pode servir de referencial para o reordenamento de condutas e valores (Figueira, 1985).

Esta é, de fato, uma explicação parcial para a importância atribuida ao conheci-

\footnotetext{
Uma das colocações mais claras neste sentido, é aquela feita por Zagury (1992).

${ }^{2}$ que, ocorrido em nosso pais no bojo de uma situação política e económica com caracteristicas peculiares, não deixa de acompanhar uma tendència mais geral dos paises ocidentais industrializados (Perrot, 1991).
} 
mento psicológico, mas que já permite situar de outra forma o problema; ou seja: se há uma crescente difusão de conhecimentos psicológicos ligados à educação da criança, há também uma demanda desses conhecimentos e que não se restringe às questões da educação infantil. Não se trata aqui de um preciosismo (já que inclusive difusão e demanda não se dão em processos absolutamente distintos), mas de uma análise: atualmente a psicologia passa a fazer parte do universo de apoio para a resolução dos problemas do homem no mundo.

Particularizando-se para a temática mais específica da educação de filhos, a transição do ideário tradicional ao moderno significou os pais se defrontarem com uma tarefa para a qual têm poucos referenciais. a educação recebida na infância já não serve de modelo, e, mesmo nos aspectos mais práticos, a novidade da tarefa passa a ser completa; com a tendência ao afastamento da família de origem a consequente centralização da vida familiar no próprio casal, e a crescente redução da extensão da prole, as novas geraçðes deixam de aprender a lidar com crianças tal como ocorria nos núcleos familiares mais extensos, onde os mais velhos partilhavam a tarefa de cuidar dos mais jovens (Dias da Silva, 1986).

Se se parte para analisar o processo de socialização ao longo do tempo, é fácil constatar que os adultos de hoje foram educados dentro de ideários mais próximos ao tradicional, e portanto assimilaram estes valores de forma profunda, porque em etapas precoces da vida e através de mecanismos de identificação básicos. Por outro lado, ao longo de sua juventude, num momento posterior de seu desenvolvimento houve uma socialização secundária (segundo o conceito de Berger \& Luckmann, 1985) através do contato com outros agentes socializadores - em especial a escola -, e a assimilação de um conjunto de valores modernos que aparentemente - mas só aparentemente ocuparam o lugar dos primitivos. No momento em que assumem o papel de educadores, esses dois conjuntos de valores entram em choque direta ou indiretamente.

$O$ resultado desta situação é apontado por algumas pesquisas que procuram identificar o ideário adotado pelos pais atualmente: mais do que a adoção de um conjunto de idéias e valores modernos, uma parcela significativa dos pais encontra-se em posições intermediárias, em que convivem elementos de ideários diferentes, caracterizando-se a vivência de uma situação de conflitos e incertezas (Nicolaci-daCosta, 1985 e 1987).

Nesse sentido é curioso constatar que tanto aparecem insatisfaçðes e conflitos claramente expressos -que em geral são acompanhados de certa tendência de retomada de valores mais tradicionais - , quanto alguns indicadores mais sutis deste conflito tais como o desejo de resultados análogos aos obtidos pelos métodos tradicionais (enquanto esses métodos em si mesmos são recusados), ou a dificuldade das mães em lidar com a indisciplina, em função da crença subjacente de que se forem oferecidas boas condiçðes à criança ela será bem comportada (Nogueira, 1962; Silva Neto, 1988; Zagury, 1992; Biasoli-Alves e Caldana, 1994; Biasoli-Alves et alli, 1994). Parece assim 
vigorar a idéia de que a educação da criança pode se dar sem limitaçð̃es, sem restriçðes - essas, tão sofridamente sentidas na própria infância, tão recusadas num mundo que diz que a indivídualidade deve ser zelosamente preservada e onde a sociedade de consumo promete ausência de sofrimentos e privaçôes! (Adorno \& Horkheimer, 1985).

É a esses educadores que a Psicologia vem falar. E aqui algumas perguntas são importantes: como (através de que meios) ela chega a eles?; e o que ela diz?

Em relação à primeira destas questð̌es, um dado inquestionável é que em termos gerais, aquilo que os leigos consideram adequado na educação coincide com os enunciados genéricos formulados pela Psicologia (Biasoli-Alves \& Caldana, 1994). E as fontes onde os educadores buscam as orientaçð̌es são predominantemente as de fundamentação -ou suposta fundamentação - cientifica: pediatras, psicólogos, livros de psicologia, manuais tais como o do Dr. Delamare, revistas tipo Cláudia e Pais ou Filhos (Dias-da-Silva, op . cit.). Destacam-se entre estas o pediatra e depois as revistas e livros; o psicólogo é um pouco mais procurado, embora ainda menos que o médico, no caso de problemas com a educação da criança (Caldana et alli, 1994).

Fica evidente assim, que mais que um contato direto com os profissionais da psicologia, o que se tem é o acesso a informações veiculadas pela mídia, ou então a orientaçðes fornecidas via pediatra. Nesses dois casos pode-se supor que existem diversos filtros, e talvez por isso mesmo faça mais sentido pensar num conjunto de informaçð̃es compatíveis com um ideário socialmente presente e não apenas num conhecimento produzido pela psicologia.

\section{Trazendo à baila um exemplo}

A análise da revista "Família Cristă', da década de 30 até o final da de 80 permite traçar certas linhas de evolução das orientações e conselhos dados aos adultos que estão no papel de educadores (Caldana, 1991). Deste trabalho alguns pontos podem ser destacados. Assim, em relação ao ideário veiculado pela revista em seu período inicial, observa-se uma conformação ao modelo tradicional: o fundamento está na religião e na sabedoria popular, tendo como ponto chave a autoridade; sua contrapartida é a preocupação com a obediencia e o bom comportamento. Interessantíssimo, no entanto, observar a minunciosidade, a precisão e adequação das regras práticas contidas nos artigos (que realmente são as que se considera capazes de mais facilmente levar à obediência estrita).

No final dos anos 50 e início dos anos 60 , em conformidade com a preocupação em adequar-se ao moderno, abre-se espaço para a presença da técnica e da ciência, inclusive no domínio da educação infantil: é preciso que se conheça a criança de tal forma a que se estimule seu desenvolvimento - e a revista traz então, tanto informações sobre o desenvolvimento quanto a descrição de condutas capazes de estimulá-lo. Em termos do relacionamento adulto-criança, as recomendações vão na direção de atitudes 
que, sem abrir mão da colocação de limites e exigências, sejam permeadas de afeto e comunicação.

No final dos anos 80 o quadro apresenta-se bastante diverso. É tônica geral a preocupação com a subjetividade e a vida emocional das pessoas, e coerentemente a psicologia, no seu enfoque clínico, é chamada a opinar em quase todos os assuntos. As direçð̋es oferecidas nestas discussð̃es são várias e assiste-se a uma fragmentação das informaçð̃es, que aparecem sem coerência e estrutura. A nível da educação destaca-se a ausência completa de orientaçðes práticas de conduta, a presença de enunciados gerais que pouco significado têm para aqueles que não dominam um vocabulário técnico, a ênfase no caráter indeterminado do processo de educação da criança visto como algo a ser constantemente criado e recriado, e a equivalência estabelecida entre educar e promover saúde emocional, sustentada principalmente pela preocupação com o patológico.

Curiosamente, no entanto, pode-se dizer que tanto nos anos 30 quanto nos anos 80 , embora sob roupagens diferentes, os adultos são considerados os responsáveis pelo sucesso ou fracasso da educação, dentro, é claro, daquilo a que ela se propunha.

Estas observaçðes, à medida em que se referem a um material veiculado pela imprensa, poderiam sem dúvida ser discutidas tendo como referêncial as características da chamada indústria cultural (Adorno, 1992) e suas relaçøes com processos sociais mais gerais. Interessa-nos mais, neste momento, no entanto, extrair material para uma reflexão que ofereça apoio e fundamentação para a prática profissional daqueles que lidam, que orientam processos educacionais.

Uma das colocaçð̃es mais sérias - que vem sendo feita tanto em relação ao contexto brasileiro quanto ao de outros países (Lasch, 1991; Zagury, op. cit.) - e que se deveria ter em mente, é a de que a difusđ̃o de conhecimentos técnicos contribui para manter os leigos com um sentimento de incapacidade e culpa no desempenho de sua tarefa de educar.

Há pesquisas, é certo, que mostram que os adultos não são consumidores tão passivos das orientações técnicas, adotando-as desde que submetidas a seu crivo pessoal ${ }^{3}$.Apesar disto, a preocupaçãocom esta colocação deve permanecer, uma vez que, ao menos no material analisado acima, fica evidente que a informaçăo transmitida pode realmente reforçar o sentimento de incapacidade (de professores, de pais), até porque a culpabilização pelo resultado obtido com a criança parece ser uma constante, e por dar margem a que se creia que educar e promover saúde emocional são a mesma coisa ${ }^{4}$.

\footnotetext{
3 o que reforça a idéia são mais propriamente as caracteristicas do que define a educação de uma criança atualmente (o seu caráter indeterminado, a auséncia de regras claramente estabelecidas , a valorização do idiossincrático - tanto do socializador quanto do socializado - , e a incorporação da preocupação com o bem estar emocional e com o controle da subjetividade) cria em grande medida a dificuldade do processo;isso num contexto em que a valorização da psicologia está intimamente ligada, é claro.

4 uma idéia bastante equivocada, conforme aponta Costa (1984).
}

Paidéia, FFCLRP-USP, Rib. Preto, 7, Agosto/1994. 
A comparação entre as revistas dos anos 50 e 80 é esclarecedora: em primeiro lugar, nos anos oitenta, tendo-se como pano de fundo a ameaça dos "problemas emocionais", não são oferecidas informaç̃es para os educadores se situarem e compreenderem um pouco ${ }^{5}$ melhor o que ocorre no desenvolvimento e socialização infantis. Além disso, orientaçð̃es através de enunciados genéricos são passíveis de serem interpretadas de forma diversa. Tome-se por exemplo o "explicar", recurso educativo que implica em dar razð̌es concretas para uma ação que no entanto pode (e em geral o faz) produzir apelo ao emocional.

Pergunta-se se os profissionais que assumem o papel de orientadores na educação não deveriam transmitir as informaçðes de que se dispõe na área, de forma clara e cuidadosa, de tal maneira a que os leigos possam servir-se delas, criticá-las, ao invés de ficarem a sua mercê?

Retome-se agora a idéia de que entre as causas das dificuldades para educar estaria o conflito entre um ideário moderno e aquele tradicional.

Se se admite a sua veracidade, novamente se colocaria a questão: será que aos leigos não deveriam ser explicitados esses modelos, de tal forma a que os pais pudessem ter maior clareza ao optar por uma das duas posturas, ou fazerem a composição que desejarem entre ambas? Qual a melhor forma de fazê-lo?

Uma forma de lidar com este aspecto é a instrumentação dos profissionais que atuam com os educadores, transmitindo-lhes conhecimentos históricos, e mais especificamente aqueles voltados para a família e preocupados com a questão das mentalidades.

Esta corrente historiográfica, ao voltar-se para a reconstrução do universo dos recursos mentais disponiveis em diferentes épocas, incluiu no seu campo de interesses a afetividade, os costumes e os valores; e tem, na familia, um objeto privilegiado (Caldana, 1993). As descriçð̃es construidas neste domínio permitem, à medida em que conseguem tornar compreensíveis e "próximos" os homens de outrora, que se entre em contato com as formas de pensar, valores e fantasias oriundas das identificaçðes estabelecidas com as geraçðes precedentes; e este processo potencialmente pode auxiliar numa releitura da própria vida através do reencontro com o mundo onde viveram seus antepassados, do qual certamente se é psiquicamente tributário.

Através deste contato torna-se possível oferecer um auxílo tanto para que o educador lide com os conflitos pessoais cuja origem estaria na coexistência (pouco explicitada ou não para a própria pessoa) entre valores modernos e tradicionais, quanto para que ele compreenda a articulação desses dois ethos com o contexto em que se inserem, de tal forma que possam fazer realmente em sua prática uma escolha entre, ou uma composição de ambos.

\footnotetext{
5 um pouco, porque na verdade a própria psicologia não compõe num conjunto coeso.
} 


\section{ABSTRACT}

This paper intends to analyse and discuss what happens in the search for orientations in childhood education, and the way the professionals, specially the psychologists, are answering to this solicitations. The approach adopted is interdisciplinary, and at the same time it is studied: a) what the adults are experiencing in their role as socializers, the difficulties and the problems faced; $b$ ) the different types of "technical and scientific" orientations passed; c) the need for another kind of support, also to understand better and to propose interventions strategies, from adjacent knowledge areas as childhood, education and family history.

\section{REFERÊNCIAS BIBLIOGRÁFICAS}

ADORNO, T. W. Teoria da semi-cultura In: OLIVEIRA, N. R. (org.) Theodor W. Adorno: quatro textos clássicos São Carlos, UFSCar/UNESP, 1992, p. 40-73 (mimeo.).

ADORNO, T. \& HORKHEIMER, M. A indústria cultural: o esclarecimento como mistificação das massas In: Dialética do esclarecimento: fragmentos filosóficos, Rio de Janeiro, Zahar, 1985, p. 113-156.

BERGER, P.L. \& LUCKMANN, T. A construção social da realidade:tratado de sociologia do conhecimento Petrópolis, Vozes, 1985.

BERMAN, M. Tudo o que é sólido desmancha no ar: a aventura da modernidade São Paulo, Companhia das Letras, 1987.

BIASOLI-ALVES, Z.M.M. \& CALDANA, R.H.L. Brazilien mothers and childrearing practices: utilized patterns and the ideal forms of education 2 nd. International Congress of Family Psychology, Padua, 1994 (mimeo.)

,DIASDA SILVA, M.H.G. \& CALDANA, R.H.L. The childrearing process in brazilien families in the last decades 23rd. International Congress of Applied Psychology, Madrid, 1994 (mimeo.).

CALDANA, R. H. L. Familia, mulher e filhos: três momentos numa revista católica brasileira São Carlos, 1991, 229 p. Dissertação(Mestrado), Centro de Educação e Ciências Humanas da Universidade Federal de São Carlos.

, História das mentalidades, Psicologia e Psicanálise: um trabalho em colaboração Rib. Prêto, 1993 (mimeo.).

, BIASOLI-ALVES,Z.M.M. \& DIAS DA SILVA, M.H.G.F. Family childrearing practices: the scientific and thecnical knowledge emergency 23rd. International Congress of Applied Psychology, Madrid, 1994 (mimeo.). 
COSTA, J. F. Saúde mental, produto da educação? In: Violência e psicanálise Rio de Janeiro, Graal, 1984, p. 63-78.

DIAS DA SILVA, M. H. G. F. A educação dos fillhos pequenos nos últimos cinquenta anos: a busca do melhor? São Paulo, 1986, 253 p. Dissertação (mestrado). Instituto de Psicologia da Universidade de São Paulo.

FIGUEIRA, S. A. Modernização da familia e desorientação: uma das raizes do psicologismo no Brasil In: Brasiliense, 1985, p. 142-6. (org.) Cultura da Psicanálise São Paulo, ,O "moderno" e o "arcaico" na nova família brasileira: notas sobre a dimensão invisível da mudança social In: (org.) Uma nova família? o moderno e o arcaico na família de classe média brasileira Rio de Janeiro, Zahar, 1987 , p. $11-30$.

LASCH, C. Refúgio num mundo sem coração. A familia: santuário ou instituição sitiada? Rio de Janeiro, Paz e Terra, 1991.

NICOLACI-DA COSTA, A. M. Mal estar na família: descontinuidade e conflito entre sistemas simbólicos In FIGUEIRA, S. A. (org.) Cultura da Psicanálise São Paulo., Brasiliense, 1985, p. 145-68.

Sujeito e cotidiano: um estudo da dimensão psicológica do social Rio de Janeiro, Campus, 1987.

NOGUEIRA, O. Família e comunidade Rio de Janeiro, INEP/MEC, 1962.

ROMANELLI, G. Famílias e camadas médias: a trajetória da modernidade. São Paulo, 1987, 343 p. Tese (Doutorado). Faculdade de Filosofia, Letras e Ciências Humanas da Universidade de São Paulo.

SILVA NETO, N. A. Fragmentos de uma metamorfose: cuidado materno e cuidado psicoterapêutico São Paulo, EDUSP, 1988.

PERROT, M. Introdução In: (dir.) História da vida privada São Paulo, Companhia. das Letras, 1991, p. 9-13, v.4.

ZAGURY, T. Sem padecer no paraiso: em defesa dos pais ou sobre a tirania dos filhos Rio de Janeiro, Record, 1992.

KEY-WORDS: Interdisciplinarity, educator's orientation, socialization, childrearing practices.

PALAVRAS CHAVE: interdisciplinaridade, orientação de educadores, socialização, práticas educativas. 